\title{
A Contínua Necessidade do Juiz em Transpor Obstáculos Epistemológicos e Superar Paradigmas na Construção do Conhecimento Científico do Direito
}

\section{The Continuous Need of the Judge in Surpassing Epistemological Obstacles and Overcoming Paradigms in the Construction of the Scientific Knowledge of Law}

\author{
Átila de Alencar Araripe Magalhães ${ }^{1}$ \\ Renata Albuquerque Lima² \\ ${ }^{1}$ Universidade de Fortaleza (UNIFOR), Fortaleza, CE, Brasil \\ ${ }^{2}$ Centro Universitario Christus (UniChristus), Fortaleza, CE, Brasil
}

Resumo: A Ciência passa por constantes refutações. Geralmente, essas refutações acabam por fazer com que a Ciência evolua. Ocorre que não há evolução sem superação do que Bachelard denominou de "obstáculos epistemológicos". Quando o Poder Judiciário modifica a sua jurisprudência ocorre uma quebra de paradigmas. Logo, o Direito evolui. O artigo que se segue versa justamente sobre a necessidade de se superar constantemente os preditos obstáculos epistemológicos, correlacionando-os com a mudança de jurisprudência do Poder Judiciário. Para tanto, estudou-se também os constructos de Thomas Kuhn. A metodologia utilizada é bibliográfica e analítica.

Palavras-chave: Obstáculos Epistemológicos. Mudança da Jurisprudência. Construção do Conhecimento do Direito.
Abstract: Science goes through constant refutations. Generally, these refutations eventually cause science to evolve. It happens that there is no evolution without overcoming what Bachelard called "epistemological obstacles". When the Judiciary modifies its jurisprudence there is a breakdown of paradigms. Therefore, Law evolves. The following article is about the need to constantly overcome the predicted epistemological obstacles, correlating with the change in the jurisprudence. Therefore, Thomas Kuhn's work was also studied. The methodology used is bibliographical and analytical.

Keywords: Epistemological Obstacles. Change in Case Law. Construction of Knowledge of Law.

Recebido em: 24/08/2018

Revisado em: 05/02/2019

Aprovado em: 25/02/2019 


\section{Introdução}

O tema a seguir desenvolvido analisa a evolução contínua da Ciência do Direito dentro de uma perspectiva de transposição de obstáculos epistemológicos e de superação de paradigmas, quando o Poder Judiciário altera a sua jurisprudência. Para tanto, estudou-se os "obstáculos epistemológicos", de Gaston Bachelard (1996), bem como os "paradigmas", de Thomas Samuel Kuhn (2005), para em seguida apontar-se a mudança da jurisprudência como fator de construção do conhecimento científico do Direito, a partir da quebra de paradigmas e da superação de óbices epistemológicos. Nesse esteio, objetiva o vertente ensaio entender como a mudança nos julgados do Poder Judiciário pode corroborar para a evolução da Ciência do Direito.

O Direito, como qualquer ramo científico, pode estancar caso não esteja sob constante questionamento. O mesmo se diga com relação à não superação habitual de paradigmas ou à não transposição de obstáculos epistemológicos. Explica-se: consoante ensina Bachelard (1996), o conhecimento científico evolui por meio de "rupturas epistemológicas sucessivas". Com efeito, o conhecimento só se faz com a desconstrução de um conhecimento anterior. E este mesmo conhecimento só progride caso se consiga superar os obstáculos epistemológicos.

Quando se opera uma mudança de posicionamento de uma corte de justiça sobre uma dada matéria, é natural que surjam aqueles que concordam e os que discordam da mudança. $O$ trabalho não tem por desiderato concordar ou discordar, ou mesmo, valorar posicionamentos jurisprudenciais, mas tão-somente demonstrar como essas mudanças são imprescindíveis para a evolução do conhecimento científico do Direito.

Um dos fatores que corroboram com a evolução do conhecimento científico é a aproximação da verdade. Nesse esteio, quando se decide um caso concreto, o julgador busca ao máximo aproximar-se da verdade dos fatos, o que é corroborado por Thomas Kuhn (2005), que simplesmente não aceita a ideia de "verossimilitude" das teorias científicas, eis que a sociedade, por mais que evolua, nunca chegará a um patamar de verdade absoluta. Em outros termos, quando um julgador decide uma causa, por 
mais subsistentes que sejam as provas dos autos, por melhor que seja a sua argumentação, não há como se chegar a um resultado (decisão judicial) que espelhe uma verdade absoluta, uma justiça plena. Com efeito, o julgador deve sempre se pautar no conjunto da obra do processo, sopesando provas e as cotejando com os fatos descritos, a fim de proferir uma decisão que seja mais justa para as partes, diante do que se apresenta naquele momento processual.

Dessa feita, uma tese adotada pelo juiz é apenas um dos caminhos, dentre muitos, para se resolver um litígio. Não há se falar, assim, em decisão melhor ou pior, mas em eficiente ou não eficiente, sob a ótica da justiça. Assim, as teses judiciais não podem ficar estanques e devem sempre ser modificadas, pois aí reside a possibilidade de sempre se construir um novo conhecimento, a partir de uma nova visão processual.

Ao contrário do que se pode pensar, o conhecimento científico não se constrói apenas por meio de um raciocínio sistêmico. Acontecimentos do cotidiano também podem fazer parte da construção do conhecimento científico. Quem faz essa afirmação é Wright Mills (1980, p. 212), para quem a sistematização do conhecimento científico pode se dar a partir de "subprodutos da vida diária", como "trechos de conversa ouvidos na rua ou, ainda, sonhos". Uma vez registrados, esses acontecimentos “[...] podem levar a um raciocínio mais sistemático, bem como emprestam uma relevância intelectual com a experiência mais direta". Do escólio de Mills, associam-se os "subprodutos da vida diária" com o depoimento testemunhal, tomado no seio de um processo judicial, por exemplo. Trata-se de um meio de prova relevante, pois muitas vezes retrata de maneira fidedigna os fatos narrados pelas partes em um feito. Contudo, às vezes, essa prova pode trair o julgador e levá-lo a incorrer em erro e a julgar mal o processo.

Importante frisar que o juiz deve ser cônscio de que a sua impressão processual pode eventualmente conter falsas premissas. Nesse contexto, calham os pensamentos de Karl Popper (1982) e Thomas Kuhn (2005), para quem hipóteses científicas são sempre passíveis de refutação, daí porque é imprescindível a sua vinculação ao empirismo, ao experimento. Com base nesse paralelo entre a decisão judicial que está sempre sofren- 
do modificações e a ciência, que está sempre sendo refutada, pergunta-se: uma decisão judicial pode ser plena, verossímil? Quando se opera uma mudança na jurisprudência dos tribunais, constrói-se um conhecimento jurídico e, consequentemente, aperfeiçoa-se a prestação jurisdicional?

É com o intuito de responder a essas indagações que os autores ordenaram as suas ideias, chegando à conclusão de que os entraves epistemológicos e os paradigmas sempre estarão presentes no momento em que o conhecimento científico é construído, ou, em que uma decisão judicial é prolatada. Logo, não há se falar em finitude do conhecimento ou em decisão judicial plena, verossímil. É que os conceitos, os paradigmas que a ciência elabora ou que o magistrado invoca em suas decisões sempre estarão suscetíveis de modificação, de aperfeiçoamento, de reconstrução.

Se o cientista realmente estiver disposto a construir um saber científico, deverá ele estar apto a identificar os referenciados empecilhos, a fim de superá-los indefinidamente, como em uma roda viva. Da mesma forma, o cientista deverá estar pronto para transpor os paradigmas científicos existentes, se ele almeja aperfeiçoar o conhecimento científico. O mesmo se aplica a um magistrado. Ele deve constantemente rever os seus conceitos e as suas ideias, a fim perfectibilizar suas decisões judiciais. Assim, identificando os obstáculos epistemológicos, é possível reconstruir os paradigmas científicos. E reconhecendo que o conhecimento jurídico precisa de contínua reciclagem, o julgador tem como melhorar sua prestação jurisdicional.

Finalmente, na elaboração deste trabalho, em termos metodológicos, optou-se por se utilizar de pesquisa bibliográfica e analítica, uma vez que se teve de estudar os constructos de autores como Bachelard e Kuhn, para poder respaldar a tese ora defendida de que a mudança de jurisprudência do Poder Judiciário ocorre quando há rupturas epistemológicas e/ ou superação de paradigmas, e, quando isso ocorre, é um fator de construção e evolução do conhecimento do Direito. 


\section{A Constante Evolução do Pensamento Científico e a sua Infinitude}

No livro "A formação do espírito científico - contribuição para uma psicanálise do conhecimento", traduzido para o português por Estela dos Santos Abreu, publicado no Rio de Janeiro, pela Editora Contraponto, em 1996, o filósofo francês, falecido em 1962, Gaston Bachelard, tratou especificamente sobre o tema "obstáculos epistemológicos". Trata-se de uma obra-referência onde os mencionados óbices bachelardianos são colocados como tudo que obstaculariza o progresso, a evolução do conhecimento científico.

Pela leitura do livro, depreende-se que Bachelard reputa que os obstáculos não podem ser encarados como problemas, mas como indicativos de que a ciência precisa sempre se reinventar, pois sempre terá óbices a transpor. Nessa linha de raciocínio, Karl Popper (1982, p. 241) afirma que o conhecimento científico tem de ser um crescendo, caso contrário, "a ciência perde seu caráter". Assim, o progresso científico é uma consequência lógica da construção do conhecimento científico.

Em um processo judicial também se vê obstáculos. Em cada contenda, observam-se surgirem óbices para a prolação de uma decisão que seja mais justa ${ }^{1}$ para as partes. Piero Calamandrei (1950, p. 25) inclusive de há muito já sustentava que o processo não pode ser vencido pela parte que eventualmente seja mais hábil, mas a que detém um melhor Direito. Nesse diapasão, convém ao julgador saber identificar esses óbices, a fim de superá-los e com isso conseguir construir uma jurisprudência que dê guarida ao melhor direito.

\footnotetext{
${ }^{1}$ Uma decisão pode ser considerada justa quando é proferida em um processo que respeita as garantias do direito público, garantias essas inflexíveis e cogentes. Em outras palavras, o processo deve respeitar o ordenamento jurídico, o qual nem o juiz e nem as partes podem dispor. Micheli Taruffo (1997, p. 318) propõe critérios para que a decisão judicial seja considerada justa, quais sejam: 1) o julgador deve saber escolher a correta regra para aplicála ao caso concreto; 2) deverá ainda o julgador saber interpretar o conjunto fático descrito no processo e, por fim; 3) deverá o juiz adotar o procedimento correto que o feito exige.
} 
Gaston Bachelard (1996, p. 17) alinha o progresso da ciência a condições psicológicas, que sempre obstacularizam a evolução do conhecimento científico. O filósofo não considera "a complexidade e a fugacidade dos fenômenos", de per si, como obstáculos epistemológicos, mas o "próprio ato de conhecer" que faz desencadear os obstáculos. Esses empecilhos identificados por Bachelard, frise-se, são o produto de suas próprias elucubrações, enquanto ser humano séquito de conhecimento, observe-se:

Quando se procuram as condições psicológicas do progresso da ciência, logo se chega à convicção de que é em termos de obstáculos que o problema do conhecimento científico deve ser colocado. E não se trata de considerar obstáculos externos, como a complexidade e a fugacidade dos fenômenos, nem de incriminar a fragilidade dos sentidos e do espírito humano: é no âmago do próprio ato de conhecer que aparecem, por uma espécie de imperativo funcional, lentidões e conflitos. É aí que mostraremos causas de estagnação e até de regressão, detectaremos causas de inércia às quais daremos o nome de obstáculos epistemológicos. (BACHELARD, 1996, p. 17)

As condições psicológicas ${ }^{2}$ do magistrado no momento da prolação de uma decisão judicial podem contribuir positiva ou negativamente para a evolução do Direito. Se o juiz nutre algum tipo de rixa ou preconceito, isso também pode influenciar o seu veredito. Jaqueline Santa Brigida Sena (2017, p. 3.147) exemplifica situações em que o juiz pode decidir desfavoravelmente a uma das partes do processo por trazer, em seu íntimo, "projeções negativas", por exemplo, com relação a negros, pessoas adeptas a religiões diferentes da sua, ex-presidiários, empregados

\footnotetext{
2 Jaqueline Santa Brigida Sena (2017, p. 3.146) aponta que "fatores extralegais" influenciam o juiz. Para ilustrar o seu posicionamento, a autora cita o filósofo do direito espanhol, Luis Recaséns Siches, o qual, de acordo com ela, “o juiz decide muito mais por intuição do que pelas orientações de ordem lógico-formal, já que ele é um ser dotado de espírito criativo e de sentimentos, aspectos que exercem marcante influência no momento de julgar". Finaliza destacando que a palavra "sentença", advém do latim sentire, que quer dizer "experimentar uma emoção, conforma aponta a Professora Dra. Lidia Reis de Almeida Prado".
} 
domésticos, motoqueiros, prostitutas, mães solteiras, homossexuais etc. Ao decidir causas que tenham como partes algum ou alguns dos exemplos citados, o magistrado poderia julgar mal, inclusive por preconceitos inconscientes, os quais, às vezes, ele não sabe ou não reconhece que tem.

Francis Bacon (1997, p. 54) é quem defendia a neutralidade do juiz no momento de julgar o caso concreto, exigindo-se deste a liberdade de prévios preconceitos, em que o sujeito aplicador do direito se libertaria completamente de tais fatores, agindo de forma completamente neutra. Dessa forma, ocorreria o não envolvimento do sujeito cognoscente com o objeto apreciado. Com esse entendimento, Bacon contraria frontalmente o pensamento de Gadamer (1997, p. 358), para quem:

[...] uma consciência formada hermeneuticamente deve, desde o princípio, mostrar-se receptiva à alteridade do texto. Mas essa receptividade não pressupõe nem uma "neutralidade" com relação à coisa nem tampouco um anulamento de si mesma; implica antes uma destacada apropriação das opiniões prévias e preconceitos pessoais. O que importa é dar-se conta dos próprios pressupostos, a fim de que o próprio texto possa apresentar-se em sua alteridade, podendo assim confrontar sua verdade com as opiniões prévias pessoais.

A complexidade das discussões e a fugacidade dos fenômenos jurídicos também podem figurar como obstáculos à prolação de uma justa decisão. Esses empecilhos devem ser enfrentados de maneira parcimoniosa, posto não se ter como colocá-los de lado. Portanto, o juiz pode ser considerado um cientista, a partir do momento em que, a partir de uma decisão judicial, constrói uma ciência. Todo magistrado possui, então, um espírito científico.

O espírito científico tratado por Bachelard no livro mencionado na abertura desse tópico é justamente a solução para a superação dos obstáculos epistemológicos. Em outras palavras, o espírito científico "[...] se constitui como conjunto de erros retificados" (BACHELARD, 1996, p. 293). Nesse conduto de exposição, como o conhecimento é infinito e possui várias facetas, não há como se chegar à sua plenitude. O importante é 
acumulá-lo com vistas a refutá-lo e, com isso, poder modificá-lo, de forma inexorável.

E assim o é com o julgador. Deve ele ser sabedor de que o seu conhecimento técnico é limitado, e que há circunstâncias psicológicas que o envolvem no momento da prolação de suas decisões, e, ainda, eventuais "projeções negativas" ou mesmo preconceitos ${ }^{3}$ devem ser cuidadosamente observados, com vistas a melhorar cada vez mais o teor de suas decisões judiciais, e assim poder contribuir para o fortalecimento e para a evolução da Ciência do Direito.

\section{Alguns Obstáculos Epistemológicos segundo Gaston Bachelard}

Bachelard (1996) enumera vários entraves ao conhecimento, que, algumas vezes, paralisam a construção do pensamento científico e podem até levar ao seu retrocesso. Nesse viés, Carlos Augusto Medeiros de Andrade (2009, p. 56) explica que o termo "obstáculo", cunhado por Bachelard, transmite uma ideia de dinamismo, movimento, de algo que precisa ser superado, transposto, "[...] demonstrando que o ambiente das ideias não é estático, inerte, mas sim, dotado de imensa agitação". É justamente a atmosfera processual. $\mathrm{O}$ processo é dinâmico ${ }^{4}$, logo, dinâmico também deve ser o raciocínio de um magistrado.

Eduardo Couture (1977, p. 43) faz alusão ao caráter dialógico do processo devido ao debate travado pelos seus partícipes - juízes, auxiliares, partes, testemunhas, peritos, etc. - que devem obediência aos preceitos legais pertinentes. Isso denota bem o dinamismo processual. Uma de-

\footnotetext{
${ }^{3}$ Os preconceitos não são considerados falsos juízos, na concepção de Gadamer (1997, p. 360), mas pelo contrário, senão veja-se: “[...] preconceito não significa, pois, de modo algum, falso juízo, uma vez que seu conceito permite que ele possa ser valorizado positiva ou negativa [...] e no procedimento da jurisprudência um preconceito é uma pré-decisão jurídica, antes de ser baixada uma sentença definitiva".

4 Sobre o dinamismo processual, sugere-se a leitura do artigo "Processo judicial e efetividade da função. Algumas reflexões”, do juiz do Tribunal de Justiça do Estado do Rio de Janeiro e Professor de Direito Processual Civil Adolpho C. de Andrade Mello Júnior.
} 
cisão proferida por um juiz que não retrata os atuais valores sociais pode levar a Ciência do Direito a um verdadeiro retrocesso ${ }^{5}$. De igual forma, o magistrado que não busca aperfeiçoar as suas decisões, em nada contribui para a melhora da Ciência do Direito.

Horácio Wanderlei Rodrigues e Leilane Serratine Grubba (2012, p. 318) também, a partir dos escólios de Bachelard, obtemperam que, para a ciência progredir, deve ela ser colocada frente a frente aos obstáculos epistemológicos, “[...] pois diante do real, aquilo que se crê saber com clareza ofusca o que se deveria saber". O conhecimento científico só pode ser alcançado, assim, após ser refutado, criticado, questionado, discutido, pois, caso contrário, as ideias seriam postas de forma dogmática, o que impediria a criação de novos paradigmas. A ideia aqui esposada foi extraída da leitura da obra de Gaston Bachelard (1996, p. 17), que sustenta que a ciência só evolui caso seja confrontada com os referidos obstáculos epistemológicos, mire-se:

Quando se procuram as condições psicológicas do progresso da ciência, logo se chega à convicção de que é em termos de obstáculos que o problema do conhecimento científico deve ser colocado. E não se trata de considerar obstáculos externos, como a complexidade e a fugacidade dos fenômenos, nem de incriminar a fragilidade dos sentidos e do espírito humano: é no âmago do próprio ato de conhecer que aparecem, por uma espécie de imperativo funcional, lentidões e conflitos. É aí que mostraremos causas de estagnação e até de regressão, detectaremos causas de inércia às quais daremos o nome de obstáculos epistemológicos.

A forma hierarquizada como o Poder Judiciário encontra-se erigido contribui para a evolução da Ciência do Direito. Uma decisão judicial, ao ser refutada pelas partes litigantes por meio da interposição de um recurso, é revista na mesma instância ou em uma instância superior ${ }^{6}$. Após a

\footnotetext{
${ }^{5}$ Robert Alexy (2005, p. 46) sustenta que uma decisão judicial deve estar sujeita à lei, deve respeitar necessariamente os precedentes e deve ser enquadrada dentro do ordenamento jurídico então vigente, respeitando-se, ainda, as regras processuais.

${ }^{6}$ Sérgio Massaru Takoi (2015), em um artigo sobre o princípio do duplo grau de jurisdição, aduz que o jurisdicionado faz jus a revisões de decisões judiciais por uma
} 
análise de um colegiado, que critica, questiona, discute entre si a matéria, sobrevém outra decisão que muitas vezes aperfeiçoa a decisão recorrida. Essa possibilidade de revisão de decisão judicial é positiva, pois, caso contrário, poder-se-ia ter inúmeras arbitrariedades, e, ao mesmo tempo, evidencia que uma decisão judicial não se constitui em um dogma, logo, passível de modificação e, portanto, de se criar um novo paradigma, de se reconhecer um novo Direito.

Tecido esse introito necessário à compreensão, pelo menos perfunctória do que seriam obstáculos epistemológicos na visão de Gaston Bachelard, conveniente agora trazer alguns desses obstáculos para serem discutidos no texto. Nessa toada, o primeiro óbice diz respeito à opinião. Para Gaston Bachelard (1996, p. 18), a opinião é sempre equivocada, razão pela qual não pode ser levada em consideração. Ademais, a construção do conhecimento científico é incompatível com "um conhecimento vulgar provisório", observe-se:

A ciência, tanto por sua necessidade de coroamento como por princípio, opõe-se absolutamente à opinião. Se, em determinada questão, ela legitimar a opinião, é por motivos diversos daqueles que dão origem à opinião; de modo que a opinião está, de direito, sempre errada. A opinião pensa mal; não pensa: traduz necessidades em conhecimentos. Ao designar os objetos pela utilidade, ela se impede de conhecê-los. Não se pode basear nada na opinião: antes de tudo, é preciso destruí-la. Ela é o primeiro obstáculo a ser superado. Não basta, por exemplo, corrigi-la em determinados pontos, mantendo, como uma espécie de moral provisória, um conhecimento vulgar provisório. O espírito científico proíbe que tenhamos uma opinião sobre questões que não compreendemos, sobre questões que não sabemos formular com clareza. (BACHELARD, 1996, p. 18)

\footnotetext{
instância superior, que se pressupõe ser composta "por juízes mais experientes", e, em regra, por um colegiado. Além disso, a revisão judicial possui "índole política", posto que é conveniente ao Estado conhecer e rever "certas decisões". Possui, ainda, uma "índole ideológica", pois permite "uma melhor reflexão sobre a decisão - diminuindo a possibilidade de erro - indo de encontro à Justiça”. Por fim, "índole psicológica”, pois o julgador é sabedor que as decisões por ele proferidas poderão ser revistas, logo tentará dar o melhor de si para não ter a sua decisão modificada.
} 
Depreende-se, das palavras de Bachelard, que o conhecimento sempre advém de uma resposta a uma indagação. Esses constantes questionamentos a que o interprete faz ao texto e as consequentes respostas resultantes dessa interpretação foram denominados, de acordo com Hans-Georg Gadamer (1997), de Fusão de Horizontes ${ }^{7}$, sendo essa uma junção do horizonte do intérprete com o do texto. É nesse sentido que Glauco Barreira Magalhães Filho (2001, p. 42-43) explica de forma didática a compreensão dessa fusão de horizontes, a seguir exposta:

A fusão de horizontes seria a fusão do horizonte do intérprete com o do texto, já que, diferentemente de Schleiermacher, Gadamer não dava importância à perspectiva psicológica do autor. O horizonte do texto seria a riqueza de sentido nele incorporada por sucessivas interpretações que lhe foram dadas no curso da história. Depois de reiteradas fusões de horizontes, tanto o horizonte do intérprete como o do texto adquiririam ampliação maior, de maneira tal que um reencontro do intérprete com o texto daria margem a novas perguntas e, consequentemente, a novas respostas.

Para Gadamer, o círculo hermenêutico teria a forma de um espiral, porquanto o sentido seria inesgotável e a compreensão sempre sujeita a ampliação e aprofundamento. Além disso, ele identificava interpretação e aplicação, pois compreender o texto seria fazer a sua aplicação ao nosso contexto existencial.

Com efeito, não havendo questionamento, não há conhecimento científico. A ciência é, assim, incompatível com a evidência, com a gra-

\footnotetext{
${ }^{7}$ De acordo com Gadamer (1997, p. 514), é resultado do processo hermenêutico a obtenção do horizonte de interpretação, a que ele reconhece como uma fusão de horizontes. Senão veja-se pequena citação de sua obra Verdade e Método: “Agora isso se confirma também a partir do caráter de linguagem da interpretação. Através da interpretação o texto deve vir à fala. Mas nenhum texto e nenhum livro falam se não falarem a linguagem que alcance o outro. Assim, a interpretação deve encontrar a linguagem correta se quiser fazer com que o texto realmente fale. Por isso, não pode haver uma interpretação correta "em si", justamente porque em cada uma está em questão o próprio texto. A vida histórica da tradição consiste na sua dependência a apropriações e interpretações sempre novas. Uma interpretação correta "em si" seria um ideal desprovido de pensamento, que desconhece a essência da tradição. Toda interpretação deve acomodar-se à situação hermenêutica a que pertence."
} 
tuidade, pois ela não nasce do acaso, mas de uma construção e reconstrução contínua do conhecimento científico. Nesse viés, parte da produção do conhecimento da Ciência do Direito advém da jurisprudência. Quanto mais questionada, construída e reconstruída a decisão judicial, mais o Poder Judiciário se debruça sobre a matéria, consequentemente, maior a probabilidade de se produzir um melhor Direito.

A “experiência primeira", também chamada de "observação primeira" por Bachelard (2006, p. 25), diz respeito ao fato de o cientista preferir a aparência das ideias do que as ideias propriamente ditas. Ou seja, o cientista confere mais importância às ferramentas por ele utilizadas do que aos resultados do seu experimento. Para Lucas Dominguini e Ilton Benoni da Silva (2010, p. 7), a experiência primeira possui "caráter acrítico" e "[...] não pode se constituir uma base segura para o conhecimento, pois está carregada de realismo e impulso natural".

Nesse obstáculo, a realidade do entorno é maximamente absorvida pelo cientista, porém de forma acrítica, o que enseja interpretações errôneas dos fatos. A solução apontada por Lucas Dominguini e Ilton Benoni da Silva (2010, p. 7-8) é "reaver a crítica", buscar "novas experiências" cotejando-as com "[...] as impressões obtidas na experiência primeira, retificando suas diferenças". E finalizam ao asserir que

[...] o empirismo deve instigar a busca de novas informações, levantar questionamentos e despertar a procura da verdade, e não produzir uma adesão imediata às primeiras concepções levantadas. (DOMINGUINI; BENONI DA SILVA, 2010, p. 8)

Essa "experiência primeira" bachelardiana pode ser facilmente transposta para o mundo processual. Quando um juiz prejulga ${ }^{8}$, quando decide uma causa sem analisá-la pormenorizadamente, há uma relativa chance de decidir mal o feito. Análises perfunctórias e acríticas são in-

${ }^{8} \mathrm{O}$ prejulgamento se caracteriza quando um juiz manifesta de forma explícita o seu convencimento acerca do mérito da causa; quando trata as partes ou os seus advogados de forma parcial; quando, de maneira desfundamentada e sistemática, indefere pleitos dos procuradores de uma das partes; quando trata de forma desrespeitosa uma das partes ou seus procuradores etc. (FRAGOSO; 2017, p. 7). 
compatíveis com o bom Direito. Com efeito, julgamentos apressados ou prejulgamentos podem importar em decisões injustas, que nada contribuem para a evolução da Ciência do Direito.

O "conhecimento geral" é outro entrave para Bachelard. Ocorre quando a explicação científica é aparentemente tão clara, que a sociedade acaba por se convencer que nada mais há a ser aprofundado ou descoberto, afastando o interesse pelo aprofundamento do conhecimento. Esse óbice acaba por paralisar a construção do pensamento científico. Gaston Bachelard (1996, p. 271) critica a procura "prematura do geral" e faz menção a possíveis tendências de se generalizar eventos diferentes sob a égide dos mesmos conceitos. O autor obtempera que é "anti-científico" sustentar um pensamento sem poder comprová-lo, ou mesmo tecer "observações gerais e imprecisas" a "causalidades entre ordens de fenômenos diferentes". Por fim, Gaston Bachelard (1996, p. 69) afirma que "Nada prejudicou tanto o progresso do conhecimento científico quanto a falsa doutrina do geral, que dominou de Aristóteles a Bacon, inclusive, e que continua sendo, para muitos, uma doutrina fundamental do saber".

Esse obstáculo epistemológico - "conhecimento geral" - é incompatível com a construção e com a evolução da Ciência do Direito. Não se produz Direito quando se tem uma decisão judicial generalista. Em um momento o qual o conhecimento científico do Direito encontra-se deveras desenvolvido, desdobrando-se em inúmeros ramos e sub-ramos, uma decisão judicial genérica não passa de um emaranhado de palavras sem qualquer sentido científico. Isto é, inservível para a construção de um pensamento jurídico dotado de substância.

Outro obstáculo é o "verbal”. O cientista, quando se utiliza de metáforas e analogias para transmitir o seu conhecimento, muitas vezes acaba por dificultar o aprendizado. Gaston Bachelard sustenta que metáforas e analogias podem ser usadas, mas somente após a transmissão da teoria. Não se sustenta, contudo, que o cientista deva afastar as suas experiências de vida de sua pesquisa. Essas experiências são válidas para o desenvolvimento do pensamento científico. Porém, esse trabalho deve ser o mais isento e científico possível. Ressalta-se que a analogia não deve ser desprezada, pois nela há uma referência, um nível dimensional. De outro 
modo, o pesquisador se utiliza de vários pontos de vista sobre o mesmo fato. Portanto, a analogia deve ser utilizada na construção do pensamento científico, a partir da reunião de "[...] dados sobre o mesmo evento ou fenômeno" tais como "entrevistas, observações e relatórios escritos" (STRAUSS; CORBIN, 2008, p. 55).

As experiências de vida de um magistrado inevitavelmente interferem nos seus julgados. Se essas interferências são positivas ou negativas, cada caso deve ser analisado de per si. O aconselhável é que as decisões judiciais sejam o mais isentas possível. Entretanto, só não pode o magistrado agir como se fosse uma máquina totalmente neutra, causando prejuízos ao seu convencimento, senão veja-se:

[...] não é aceitável falar-se em uma neutralidade pura, absoluta, como se o julgador fosse máquina, sem sentimentos, sem passar por angústias, acrítico, que simplesmente atua ditando a letra morta da lei, pois, a ele é dada a tarefa de dar vida à letra da lei. Para tanto necessita fazê-lo de forma reflexiva e crítica, valendo-se das lacunas deixadas pelo legislador burguês no ordenamento jurídico, sob pena de não conseguir alcançar justiça em suas decisões. (RAMIRO, 2008, p. 12)

A experiência de vida tem de ser tomada em nível apenas dimensional, a fim de não prejudicar a isenção do magistrado. No tocante à utilização de metáforas em decisões judiciais, não há qualquer vedação, desde que a decisão esteja devidamente fundamentada, clara e não haja margem para alegações de omissão, obscuridade, contradição ou erro material.

Gaston Bachelard (1996, p. 91) se utiliza da analogia para vincular a imagem ou palavra "esponja" ao pensamento científico. Trata-se de um termo plurisignificativo, como bem identifica o referido autor no trabalho "de Réaumur, publicado nas Mémoires de VAcadémie Royale des Sciences”, em 1731, observe-se:

Aqui, vamos tomar a simples palavra esponja e veremos que ela permite expressar os fenômenos mais variados. Os fenômenos são expressados: já parece que foram explicados. São reconhecidos: já parece que são conhecidos. Nos fenômenos designados pela palavra 
esponja, o espírito não está sendo iludido por uma potência substancial. A função da esponja é de uma evidência clara e distinta, a tal ponto que não se sente a necessidade de explicá-la. Ao explicar fenômenos por meio da palavra esponja, não se terá a impressão de cair num substancialismo obscuro; também não se terá a impressão de fazer teorias, já que se trata de uma função toda experimental. À esponja, corresponde, portanto, um denkmittel ${ }^{9}$ do empirismo ingênuo. (BACHELARD, 1996, p. 91-92)

Após evidenciado que um termo, uma palavra podem ter vários significados, inevitável se indagar: as analogias ao menos auxiliam a pesquisa? Gaston Bachelar (1996, p. 109) responde negativamente, eis que elas "provocam fugas de ideias; impedem a curiosidade homogênea que faz com que a paciência siga uma sequência de fatos bem definida". Portanto, o obstáculo "verbal", que diz respeito à utilização de metáforas e analogias por parte do cientista, quando da transmissão do seu conhecimento, tende a dificultar o aprendizado.

Já no campo da Ciência do Direito, a analogia ${ }^{10}$ é tida como fonte de direito. Nesse sentido, esse obstáculo epistemológico não pode ser considerado efetivamente um óbice à construção do conhecimento do Direito. Pelo contrário, uma decisão judicial que se utiliza de analogia para suprir uma ausência normativa deve ser vista positivamente, pois não deixa o jurisdicionado no limbo de uma omissão legislativa.

O “conhecimento unitário e pragmático" também é citado como entrave epistemológico. O mundo é visto como algo uno e harmonioso. Nesse sentido, um fenômeno natural pode ser descrito de formas diferentes. Em caso de proibições de descrições diferentes, o conhecimento científico acaba por não evoluir. Gaston Bachelard (1996, p. 112) transmite

\footnotetext{
${ }^{9}$ Denkmittel é uma palavra composta de origem alemã, que traduz a ideia de "pensamento positivo", "marco das hipóteses", "meio ou instrumento para pensar". É um termo técnico utilizado por William James em suas obras filosóficas. Disponível em: http://www. buenastareas.com/ensayos/Un-Ejemplo-De-Obst\%C3\%A1 culo-Verbal/2263033.html. Acesso em: 26 nov. 2016.

${ }^{10} \mathrm{O}$ conceito de Francesco Ferrara (1921, p. 227) acerca da analogia como fonte do direito é o seguinte: “[...] ela é a aplicação de um princípio jurídico que a lei estabelece, para $[\ldots]$ certo fato, a [...] outro fato não regulado mas juridicamente semelhante ao primeiro".
} 
a ideia de que esse conhecimento unitário e pragmático já fora superado na atualidade, eis que a ciência de hoje se constrói a partir de "sistemas isolados", mire-se:

De fato, a ciência contemporânea se instrui sobre sistemas isolados, sobre unidades parcelares. Ela sabe manter sistemas isolados. No que se refere aos princípios epistemológicos, a ciência contemporânea afirma que as quantidades desprezíveis devem ser desprezadas. Não basta dizer que elas podem ser desprezadas. Cortam-se, portanto, as determinações puramente plausíveis e nunca provadas. (BACHELARD, 1996, p. 112)

Consoante visto, a ciência necessariamente sofre rupturas para que evolua. Essas rupturas são essenciais para essa evolução e os obstáculos epistemológicos sempre existirão nesse percurso da ciência, cabendo ao cientista contorná-los na busca mais próxima de verossimilitude. Ao decidir uma causa inédita no judiciário, o julgador inova e produz um novo Direito. Em todo processo, vê-se inúmeros obstáculos, cabendo ao aplicador do direito transpô-los, a fim de proferir uma decisão que seja mais justa para as partes e, com isso, poder-se contribuir para a evolução da Ciência do Direito. Por fim, o conhecimento científico, plasmado em decisões judiciais, assim como a linguagem nelas empregada também precisam ser constantemente reconstruídos, mediante contínuas interações, críticas e discussões, visando à modificação do que foi produzido, com o objetivo de fazer com que a Ciência do Direito esteja em constante evolução.

\section{A Superação de Paradigmas como Algo Necessário à Evolução do Pensamento Científico}

Após estudados alguns dos obstáculos epistemológicos bachelardianos e após relacioná-los com parte da construção da Ciência do Direito, por meio de decisões judiciais, chegou-se à conclusão de que esses ditos óbices não podem ser encarados como problemas, mas como indicativos de que a ciência precisa sempre se reinventar, pois sempre terá empeci- 
lhos a transpor. Isso tanto se aplica à ciência como um todo, como com a ciência do direito. Além disso, o conhecimento científico tem de ser encarado como algo em constante metamorfose, caso contrário, não há progresso científico. Até porque, na qualidade de ciência social ${ }^{11}$, o Direito tem de acompanhar as transformações sociais que ocorrem no seio da sociedade. Nesse tópico, apresentar-se-á a superação de paradigmas também como algo necessário à evolução do conhecimento científico. Então, o que seria "paradigma"?

Marcela Varejão (2017, p. 14) afirma que o paradigma seria mais do que uma teoria. A razão dessa afirmação, segundo a autora, é que ele "define implicitamente quais são os problemas e os métodos legítimos a serem utilizados num determinado campo de pesquisa". Complementa a autora, dizendo que os paradigmas são

[...] complexas matrizes disciplinares, que numa comunidade científica produzem o compartilhamento entre os membros de crenças num modelo, valores, generalizações simbólicas, concretas soluções de problemas que são alçados a exemplares encontráveis em manuais, laboratórios etc. (VAREJÃO, 2017, p. 14).

O termo "paradigma" pode ser observado sob duas perspectivas. "De um lado, indica toda a constelação de crenças, valores, técnicas etc., partilhadas pelos membros de uma comunidade determinada. De outro, denota um tipo de elemento dessa constelação" (KUHN, 2005, p. 220). Em outros termos, entende-se por "paradigma" um padrão seguido por dada sociedade; um modelo; uma representação; uma interpretação do mundo que ofertará soluções-modelo para a sociedade.

11 Roy Reis Friede (2017) classifica a Ciência do Direito como Ciência Social e hermenêutica, eis que o seu foco se projeta na observação de fenômenos sociais e desenvolve "um sistema peculiar de interpretação de fatos sociais que não se limita, de nenhuma maneira, à simples valoração intrínseca dos mesmos". Complementa o autor que a referenciada ciência concebe norma jurídica (fase legislativa), e, ainda, "permite ultrapassar a concepção fundamental interpretativa, reprocessando a conclusão (ou, em outras palavras, a própria norma) e concebendo, desta feita, uma segunda norma (de aplicação) no contexto de um sinérgico processo hermenêutico (fase judicial)". 
A partir da estruturação de um estudo sobre "paradigma", Thomas Kuhn enquadra a teoria dentro do contexto de seu tempo, e despreza a ciência do hoje. Nesse sentido, os paradigmas, em verdade, são "[...] um conjunto de ilustrações recorrentes e quase padronizadas de diferentes teorias nas suas aplicações conceituais, instrumentais e na observação" (KUHN, 2005, p. 67).

Atualmente, vive-se um novo paradigma científico. Quem defende essa tese é Boaventura de Sousa Santos (1988), para quem vigora uma nova racionalidade científica. Trata-se de um modelo totalitário, segundo o autor, eis que há patente negação do "caráter racional a todas as formas de conhecimento que se não pautarem pelos seus princípios epistemológicos e pelas suas regras metodológicas". Em outras palavras, o conhecimento científico que não decorre de princípios metodológicos e/ou regras metodológicas não pode ser assim considerado. A ciência evoluiu, e com essa evolução, surgiram inúmeros ramos científicos com autonomia, metodologia e principiologia próprias.

A Ciência do Direito é um exemplo de ciência autônoma. Porém, essa autonomia não quer dizer que seja uma ciência isolada, mas uma ciência com conexão com outros ramos científicos. Esse é o escólio de André Santos Campos (2011, p. 36), observe-se:

[...] o direito será composto sobretudo por uma interdisciplinaridade intrínseca. No fundo, há uma autonomia disciplinar do direito que opera por inclusão de instrumentos multidisciplinares, isto é, a "natureza do direito" enquanto disciplina é considerada suficientemente ampla ao ponto de ser multitemática e interdisciplinar em si mesma. Por conseguinte, autonomia aqui não significa exclusividade, mas inclusividade, ou seja, não é autismo, mas autodeterminação por meio de interpenetração multidisciplinar. A unidade científica do direito envolve então uma disciplina da relação, isto é, a multiplicação temática em comércio permanente. (CAMPOS, 2011, p. 36)

Um ramo científico ganha autonomia, enquanto ciência, quando estabelece os seus paradigmas. A maturidade científica é atingida quando o pesquisador consegue definir os seus principais pontos de divergência. 
A mecânica de Aristóteles, a óptica de Newton, a química de Boyle, a teoria da eletricidade de Franklin estão entre os exemplos dados por Kuhn de paradigmas que fizeram algumas disciplinas adentrarem a fase científica.

Não se tem como elencar os elementos formadores do paradigma. A razão disso é que o conhecimento de um paradigma é, em parte, tácito, adquirido pela exposição direta ao modo de fazer ciência determinado pelo paradigma. Assim,

Na medida em que o estudante progride de seu primeiro ano de estudos em direção à sua tese de doutoramento, os problemas a enfrentar tornam-se mais complexos, ao mesmo tempo em que diminui o número dos precedentes que poderiam orientar o seu estudo. Mas, mesmo assim, esses problemas continuam a moldar-se rigorosamente de acordo com as realizações científicas anteriores, o mesmo acontecendo com os problemas que normalmente o ocuparão durante a sua carreira científica posterior, levada a cabo independentemente. Pode-se supor que em algum momento de sua formação o cientista abstraiu intuitivamente as regras do jogo para seu próprio uso - mas temos poucas razões para crer nisso. Embora muitos cientistas falem com facilidade e brilho a respeito das hipóteses individuais que subjazem numa determinada pesquisa em andamento, não estão em melhor situação que o leigo quando se trata de caracterizar as bases estabelecidas do seu campo de estudos, seus problemas e métodos legítimos. Se os cientistas chegam a aprender tais abstrações, demonstram-no através de sua habilidade para realizar pesquisas bem sucedidas. Contudo, essa habilidade pode ser entendida sem recurso às regras hipotéticas do jogo. (KUHN, 2005, p. 72)

Um paradigma fundamenta, assim, as atividades desenvolvidas pelos cientistas. Ele possui uma representação "cartográfica", que é utilizada pelos cientistas quando exploram a natureza. Kuhn denomina os estudos calcados em teorias, metodologias próprias e exemplos de um paradigma como ciência normal. Esses estudos fazem depreender "[...] que os paradigmas orientam as pesquisas, seja modelando-as diretamente, seja através de regras abstratas" (KUHN, 2005, p. 72). Assim, a ciência normal somente consegue evoluir sem regras, sem paradigmas próprios, 
até o momento em que a comunidade científica acata, sem qualquer questionamento, as soluções de problemas já alcançadas.

Em outras palavras, a investigação de fenômenos não poderá findar de maneira exitosa, enquanto não se delinearem princípios, metodologias e paradigmas próprios, que autorizem selecionar, avaliar e criticar o fenômeno observado. Nos dias atuais, é consabido que a comunidade científica reconhece situações fáticas e teorias como interdependentes. Os fatos dão suporte às teorias e estas criam os respectivos paradigmas. Quando esses paradigmas são construídos, o cientista consegue impulsionar a ciência. E quando esses paradigmas são desconstruídos e substituídos por outros paradigmas ocorre uma verdadeira revolução científica.

Quando o cientista cria princípios teóricos e regras metodológicas, a cada nova pesquisa, os princípios e os métodos tradicionais são revistos; são revisados. Thomas Kuhn faz uma analogia entre a ciência normal e a montagem de "quebra-cabeças", os chamdos puzzles, pelo fato dos "quebra-cabeças" serem agrupados e montados de forma ordenada e seguirem um parâmetro bem definido. Quem apresenta esses "quebra-cabeças" é a natureza. É assim na ciência. Com efeito, quando esses puzzles se mostram difíceis de serem montados, cabe ao cientista estabelecer paradigmas que possam viabilizar soluções para se resolver o problema. Trata-se de uma tarefa árdua que o cientista deve encarar, insistindo na revisão de regras e princípios paradigmáticos, com o fito de superar o conhecimento prévio já adquirido.

Essa superação de paradigmas, que deságua na evolução do conhecimento científico, é chamada por Thomas Kuhn de revolução científi$c a$. Esse autor se notabilizou por criar teses filosóficas sofisticadas que explicam como ocorrem as revoluções científicas. Nessa ótica, quando o conhecimento científico evolui, o cientista amadurece e passa a adotar determinadas posições "a favor de determinados valores". E isso ocorre devido ao fato desse homem vislumbrar na ciência ideias "claras" e "transparentes", por meio da produção de conceitos de realidades empíricas (WEBER, 1998, p. 84-85).

Nesse trilhar, obtempera Boaventura de Sousa Santos (1989, p. 40) que a sociedade caminha "[...] para uma nova relação entre a ciência e o 
senso comum, uma relação em que qualquer deles é feito do outro e ambos fazem algo de novo". A ruptura epistemológica modifica tanto o senso comum como a ciência. Nesse sentido, conclui Boaventura de Sousa Santos (1989, p. 40), que "[...] enquanto a primeira ruptura é imprescindível para constituir a ciência, mas deixa o senso comum tal como estava antes dela, a segunda ruptura transforma o senso comum com base na ciência".

Essa dupla ruptura não quer dizer que a segunda anula a primeira ou que, após esta segunda ruptura, se retorne ao senso comum. Pelo contrário, enquanto a primeira ruptura é imprescindível para constituir a ciência, a segunda transforma o senso comum com base na ciência. Trata-se de combinar o caráter prático e prudente do senso comum com o caráter segregado e elitista da ciência. A dupla ruptura procede a um trabalho de transformação tanto do senso comum como da ciência.

\section{Conclusão}

Com base no exposto, verificou-se que a transposição dos obstáculos epistemológicos e a superação dos paradigmas são necessárias para a evolução do conhecimento científico. Inclua-se nesse conhecimento científico a Ciência do Direito, que apesar de ser uma ciência autônoma, é inter e transdisciplinar, pois se relaciona com inúmeros outros campos científicos. Com efeito, essa evolução do conhecimento científico ocorre quando as noções do cotidiano e os conhecimentos construídos são modificados. Essa conclusão só foi possível com o estudo dos “obstáculos epistemológicos" bachelardianos e com o estudo dos "paradigmas", de Thomas Samuel Kuhn.

Os autores buscaram, assim, a partir dos escólios de Bachelard e Kuhn, contribuir para o progresso do conhecimento científico, em especial o conhecimento científico da Ciência do Direito, a partir da prolação de decisões judiciais que são discutidas e modificadas pela estrutura hierárquica do Poder Judiciário. Gaston Bachelard foi o responsável pela ruptura das epistemologias anteriores ao século $\mathrm{XX}$, fundamentando-se na teoria da relatividade e na mecânica quântica. Por sua vez, Thomas 
Samuel Kuhn estabeleceu que, quando paradigmas são construídos e/ou superados, o cientista consegue impulsionar a ciência. E quando esses paradigmas são desconstruídos e substituídos por outros paradigmas ocorre uma verdadeira revolução científica.

Diante disso, é forçoso concluir que não é possível delimitar as fronteiras do conhecimento científico. Muito menos limitar o conhecimento do Direito. É que a ciência é composta de pensamentos vivos e ativos, o que faz depreender que o conhecimento científico é efêmero, posto que é constantemente ultrapassado, superado por outros conhecimentos científicos. O ponto de partida da ciência deve ser sempre um problema. A partir dele, constrói-se uma hipótese, para, assim, poder-se resolver o referenciado problema. Assim, para Gaston Bachelard, só pode haver evolução, progressão da ciência, quando os obstáculos epistemológicos são superados e para Thomas Samuel Kuhn, as revoluções científicas ocorrem quando se consegue superar paradigmas.

Essas lições podem ser perfeitamente transpostas para a Ciência do Direito. Conforme se observou, o mundo jurídico é repleto de obstáculos epistemológicos e de paradigmas. Um magistrado, por meio de suas decisões judiciais, pode contribuir para a melhora do Direito se ele é cônscio de que esses ditos óbices não podem ser encarados como problemas, mas como indicativos de que o Direito precisa sempre se reinventar, caso contrário, não há progresso científico. Até porque, na qualidade de ciência social, o Direito tem de acompanhar as transformações sociais que ocorrem no seio da sociedade, superando os seus paradigmas em uma constante.

\section{Referências}

ALEXY, Robert. Teoria da Argumentação Jurídica: a teoria do discurso racional como teoria da fundamentação jurídica. 2. ed. Tradução de Zilda Hutchinson Schild Silva. São Paulo: Landy Editora, 2005.

ANDRADE, Carlos Augusto Medeiros de. Obstáculos epistemológicos. In: VASCONCELOS, Arnaldo; ARAGÃO, Nilsiton Rodrigues de Andrade; VIANA, Renata Neris. Temas de epistemologia jurídica. 1. ed. Fortaleza: Universidade de Fortaleza, 2009. p. 55-74. 
BACHELARD, Gaston. A formação do espírito científico: contribuição para uma psicanálise do conhecimento. Rio de Janeiro: Contraponto, 1996.

BACON, Francis. Novum Organum ou Verdadeiras indicações acerca da interpretação da natureza. Tradução de José Aluysio Reis de Andrade. São Paulo, SP: Editora Nova Cultura, 1997.

CALAMANDREI, Piero. Il processo come giuoco Rivista del Diritto Processuale, Padova, Cedam,p. 23-51, 1950.

CAMPOS, André Santos. A autonomia do direito como imanência interdisciplinar: reflexões a partir da querela entre Gustav Hugo e Hegel. [2011].Disponível em: http://revistaseletronicas.pucrs.br/ojs/ index.php/veritas/article/viewFile/9713/7312. Acesso em: 28 jan. 2017.

COUTURE, Eduardo J. Introdução ao Estudo do Processo Civil. Tradução de Mozart Victor Russomano. Rio de Janeiro: Forense, 1977.

DOMINGUINI, Lucas; BENONI DA SILVA, Ilton. Obstáculos à construção do espírito científico: reflexões sobre o livro didático. [2010]. Disponível em: http://www.ucs.br/ucs/tplcinfe/eventos/cinfe/ artigos/artigos/arquivos/eixo tematico10/OBSTACULOS $\% 20 \mathrm{~A} \% 20$ CONSTRUCAO\%20DO\%20ESPIRITO\%20CIENTIFICO.pdf. Acesso em: 25 out. 2016.

FERRARA, Francesco. Trattato di diritto civile italiano. Roma: [s.n.], 1921.

FRAGOSO, Christiano. Prejulgamento induz suspeição. [2017].

Disponível em: http://www.egov.ufsc.br/portal/sites/default/files/ anexos/11333-11333-1-PB.pdf. Acesso em: 27 jan. 2017.

FRIEDE, Roy Reis. O Direito como ciência. [2017]. Disponível em: http://www.egov.ufsc.br/portal/sites/default/files/anexos/24987-24989-1PB.htm. Acesso em: 28 jan. 2017.

GADAMER, Hans-Georg. Verdade e método I: traços fundamentais de uma hermenêutica filosófica. Tradução de Flávio Paulo Meurer. Petrópolis, RJ: Vozes, Bragança Paulista, SP: Editora Universitária São Francisco, 1997. 
KUHN, Thomas. A estrutura das revoluções científicas. 9. ed. São Paulo: Perspectiva, 2005.

MAGALHÃES FILHO, Glauco Barreira. Hermenêutica e unidade axiológica da constituição. Belo Horizonte: Mandamentos, 2001.

MELLO JÚNIOR, Adolpho C. de Andrade. Processo judicial e efetividade da função: algumas reflexões. [2017]. Disponível em: http:// portaltj.tjrj.jus.br/c/document_library/get_file?uuid=dee66654-436f4e8e-a767-d7e29c869bb3\&groupId=10136. Acesso em: 26 jan. 2017.

POPPER, Karl Raymund. Conjecturas e refutações. Tradução de Sérgio Bath. 2. ed. Brasília, DF: Ed. Universidade de Brasília, 1982.

RAMIRO, Caio Henrique Lopes. Imparcialidade e Neutralidade: identidade? [2008]. Disponível em: http://www.ihj.org.br/pdfs/Artigo_ Caio_Imparcialidade.pdf. Acesso em: 25 jan. 2017.

RODRIGUES, Horácio Wanderlei; GRUBBA, Leilane Serratine. Bachelard e os obstáculos epistemológicos à pesquisa científica do direito. [2012]. Disponível em: http://www.scielo.br/scielo. php?script $=$ sci_arttext\&pid $=$ S2177-70552012000100013. Acesso em: 31 out. 2016.

SENA, Jaqueline Santa Brigida. O juiz e a sombra: uma análise dos fatores extralegais que influenciam a atuação judicial a partir da psicologia analítica. [2017]. Disponível em: http://www.publicadireito. com.br/conpedi/manaus/arquivos/anais/sao_paulo/2515.pdf. Acesso em: 26 jan. 2017.

SOUSA SANTOS, Boaventura de. Introdução a uma ciência pósmoderna. 4. ed. Rio de Janeiro: Graal, 1989. p. 31-45.

SOUSA SANTOS, Boaventura de. Um discurso sobre as ciências na transição para uma ciência pós-moderna. [1989].

Disponível em: http://www.scielo.br/scielo.php?script=sci arttext\&pid=S0103-40141988000200007. Acesso em: 28 jan. 2017.

STRAUSS, Anselm; CORBIN, Juliet. Pesquisa qualitativa: técnicas e procedimentos para o desenvolvimento da teoria fundamentada. Porto Alegre: Artmed, 2008. p. 47-62. 
TAKOI, Sérgio Massaru. O princípio do duplo grau de jurisdição é materialmente constitucional? [2015]. Disponível em: http://www. cartaforense.com.br/conteudo/artigos/o-principio-do-duplo-grau-dejurisdicao-e-materialmente-constitucional/14851. Acesso em: 27 jan. 2017.

TARUFFO, Micheli. Idee per una teoria della decisione giusta. Rivistra Trimestrale di Diritto e Procedura Civile, Milano: Giuffrè, marzo, p. 315-328, 1997.

WEBER, Max. A "objetividade" do conhecimento da ciência social e na ciência política. In: OLIVEIRA, Paulo de Salles (org.). Metodologia das ciências humanas. São Paulo: Unesp, 1998. p. 81-105.

WRIGHT MILLS, Charles. A imaginação sociológica. Rio de Janeiro: Zahar, 1980.

Átila de Alencar Araripe Magalhães é Pós-doutorando em Direito pela Universidade Federal de Santa Catarina (UFSC). Doutor em Direito Constitucional pela Universidade de Fortaleza (UNIFOR). Mestre em Administração de Empresas pela Universidade de Fortaleza (UNIFOR). Especialista em Direito e Processo Tributários pela Universidade de Fortaleza (UNIFOR) e especialista em Direito Empresarial pela Universidade Estadual do Ceará (UECE). É professor de Direito Processual Civil da Universidade de Fortaleza (UNIFOR), na Cidade de Fortaleza, CE, Brasil. Advogado.

E-mail: atila@leiteararipe.adv.br

Endereço residencial: Rua Rafael Tobias, n. 2.240, casa 600, Bairro José de Alencar, Fortaleza, CE. CEP. 60.833-196.

Renata Albuquerque Lima é Pós-Doutora em Direito pela Universidade Federal de Santa Catarina (UFSC). Doutora em Direito Constitucional pela Universidade de Fortaleza (UNIFOR). Mestre em Direito Constitucional pela Universidade Federal do Ceará (UFC). Graduada em Direito pela UFC e em Administração de Empresas pela UECE. Professora do Programa de Pós-Graduação (Mestrado) 
da UNICHRISTUS. Professora Adjunta do Curso de Direito da Universidade Estadual Vale do Acaraú (UVA). Coordenadora do Curso de Direito da Faculdade Luciano Feijão (FLF). Advogada.

E-mail: realbuquerque@yahoo.com

Endereço residencial: Rua Rafael Tobias, n. 2.240, casa 600, Bairro José de Alencar, Fortaleza, CE. CEP: 60.833-196. 